\title{
Central retinal artery occlusion in a patient with ANCA-negative Churg-Strauss syndrome
}

This article was published in the following Dove Press journal:

Clinical Ophthalmology

30 July 2012

Number of times this article has been viewed

Yuji Kumano'

Noriko Yoshida ${ }^{2}$

Satoru Fukuyama ${ }^{3}$

Masanori Miyazaki

Hiroshi Enaida ${ }^{2}$

Takaaki Matsui'

'Ohshima Hospital of Ophthalmology, Fukuoka, ${ }^{2}$ Department of

Ophthalmology, ${ }^{3}$ Research Institute for Diseases of the Chest, Graduate School of Medical Sciences, Kyushu University, Fukuoka, Japan
Correspondence: Yuji Kumano Ohshima Hospital of Ophthalmology, I I-8 Kamigofuku, Hakata-ku, Fukuoka 8I2-0036, Japan

Tel +81922813020

Fax +819228I 5407

Email ohshimah@mocha.ocn.ne.jp
Abstract: Ocular involvement in Churg-Strauss syndrome is infrequent. We describe the case of a 54-year-old woman with eosinophilia and involvement of the respiratory tract, skin, and peripheral nervous system, fulfilling the American College of Rheumatology criteria for Churg-Strauss syndrome. The patient presented with acute, painless vision loss in her right eye. Central retinal artery occlusion (CRAO) without accompanying retinal vasculitis was diagnosed by angiographic findings and funduscopic findings of retinal whitening with a cherry-red spot. Although her antineutrophil cytoplasmic antibody (ANCA) status was negative, CRAO was thought to be an ocular manifestation of Churg-Strauss syndrome, and appropriate treatment was planned. She was treated with high-dose corticosteroids and anticoagulant therapy. Her macular edema improved, but visual recovery was poor. Specific therapy to alter inflammation, blood coagulation, and rheology reportedly plays an important role in ANCA-positive patients with Churg-Strauss syndrome who develop CRAO. Regardless of ANCA status, high-dose corticosteroids should be considered for CRAO in patients with Churg-Strauss syndrome, as discussed in this case.

Keywords: CRAO, ANCA, Churg-Strauss syndrome

\section{Introduction}

Churg-Strauss syndrome, initially described as "allergic granulomatosis and angiitis," is a systemic disease consisting of pulmonary and systemic small vessel vasculitis with elevated eosinophil counts and extravascular granulomata. ${ }^{1}$ The three major histological criteria required for diagnosis of this syndrome are prominent eosinophilic infiltration, necrotizing or granulomatous small vessel vasculitis, and extravascular granulomata.

This rare syndrome can present with various ocular manifestations. ${ }^{2}$ Anterior segment involvements include episcleritis, panuveitis, allergic granulomatous nodules of the eyelid and conjunctiva, and marginal ulcerative keratitis. Posterior segment involvements include severe panuveitis with retinal infarction, branch or central retinal artery occlusion, and optic disc vasculitis. Bilateral cases of central retinal artery occlusion (CRAO) that carries a very severe visual prognosis have been reported., The orbit can also be affected, which is described as orbital pseudotumor. Patients with Churg-Strauss syndrome may also present with neuro-ophthalmologic manifestations, including ischemic optic neuropathy, amaurosis fugax, and cranial nerve neuropathies, especially superior oblique palsy.

Notably, Churg-Strauss syndrome was associated with the presence of antineutrophil cytoplasmic antibody (ANCA) in 67\% of the patients reported 
by Guillevin et al, and most of the patients had the perinuclear ANCA (myeloperoxidase [MPO]-ANCA) pattern. 5,6 Takanashi et $\mathrm{al}^{7}$ classified ocular manifestations in Churg-Strauss syndrome into two groups, ie, ischemic vasculitis type and inflammatory pseudotumor type. Ischemic vasculitis-type manifestations including CRAO were associated with a positive ANCA status and sudden onset of loss of vision. In contrast, pseudotumor-like manifestations involved a negative ANCA status, chronic onset, red eyes, and orbital abnormalities on computed tomography. We had a patient with Churg-Strauss syndrome who developed CRAO despite an ANCA-negative status. This observational case report is important because a relationship between ANCA and CRAO in Churg-Strauss syndrome can be speculated.

\section{Case report}

A 54-year-old Japanese woman with a medical history including bronchial asthma, weight loss, dilated cardiomyopathy, hypereosinophilia, purpuric vasculitis, peripheral neuropathy, and eosinophilic pneumonia was diagnosed with advanced Churg-Strauss syndrome by American College of Rheumatology criteria. ${ }^{1}$ Oral prednisolone $30 \mathrm{mg} /$ day was given until her symptoms improved.

When her prednisolone was decreased to $10 \mathrm{mg}$ on November 12, 2008, she experienced a sudden loss of vision in the right eye and presented to us. Ocular examination showed that visual acuity was hand motion in the right eye and 25/20 in the left eye. Slit-lamp examination and intraocular pressure were normal. Funduscopy revealed retinal whitening and a cherry-red spot (Figure 1A). Three days later, retinal whitening became marked and soft exudates appeared (Figure 1B), in which macula edema was confirmed by optical coherence tomography. Left funduscopy was within normal limits. A fluorescein angiogram of the right eye showed delayed filling of the retinal artery. Late filling of the cilioretinal artery was seen at $>30$ seconds, and a choroidal perfusion defect was also observed (Figure 2A). Venous lamellar flow was observed at 43 seconds (Figure 2B). Finally, perfusion of the retinal arterioles was completed at 48 seconds. There was no leakage secondary to vasculitis from the posterior pole retinal vessels (both arteries and veins) or optic disc, and CRAO in the right eye was diagnosed.

When she developed CRAO, laboratory data showed eosinophilia $(17.6 \%$, normal value $<4 \%$ ), but other parameters, including C-reactive protein, white blood cell count, and blood coagulation, were within normal limits.

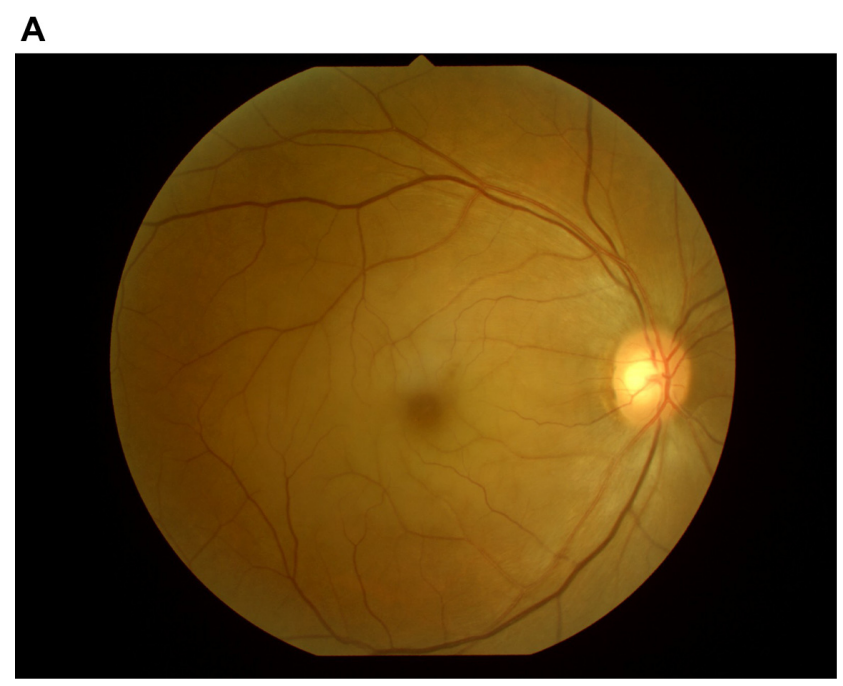

B

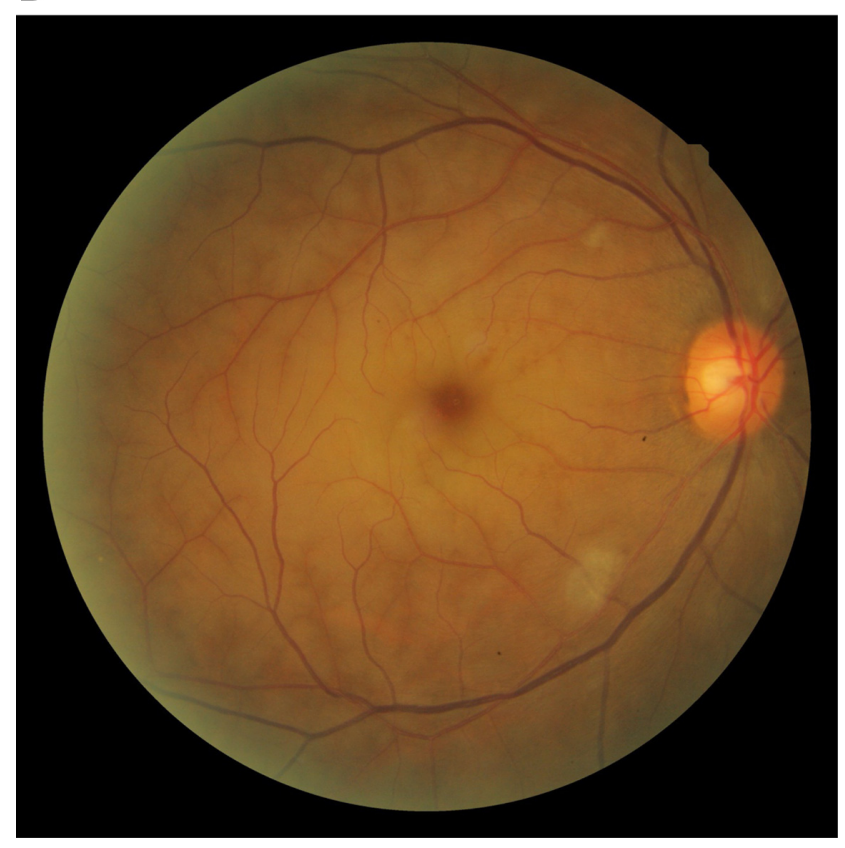

Figure I Color photograph of the right fundus showing a cherry-red spot in the macula (A). Retinal whitening became marked with soft exudates (B).

Both proteinase-3-ANCA and MPO-ANCA were also negative. The likely cause of CRAO was underlying vasculitis associated with the systemic condition and secondary localized thrombosis under the hypercoagulable state.

Intravenous urokinase was given within 6 hours of onset of symptoms. High-dose intravenous steroids (40 mg/day) were also started one day after onset, resulting in gradual improvement of macular edema confirmed by optical coherence tomography on December 5, 2008. Vision in the right eye recovered for a while but was poor (no better than 20/400), and central scotoma remained. 


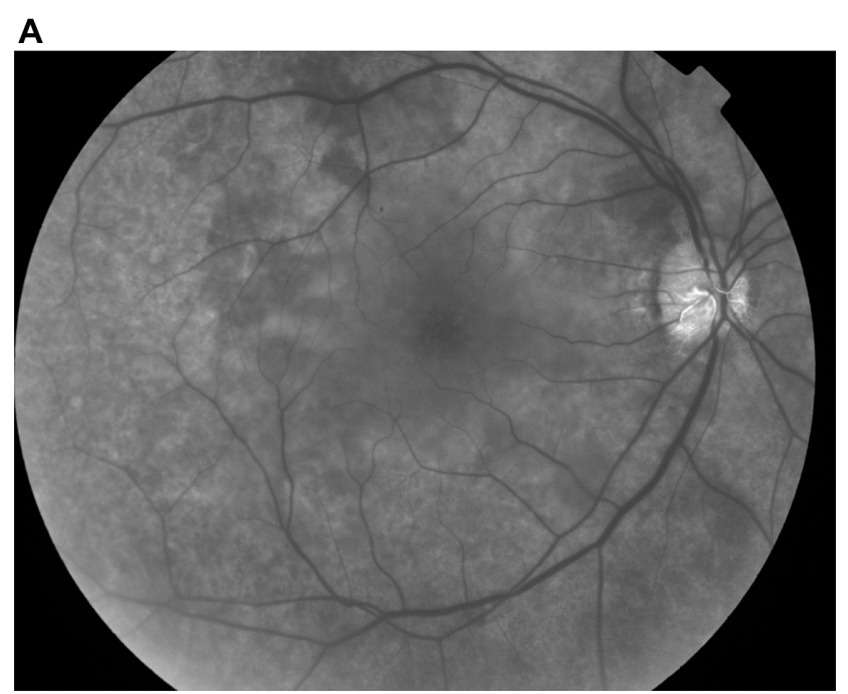

B

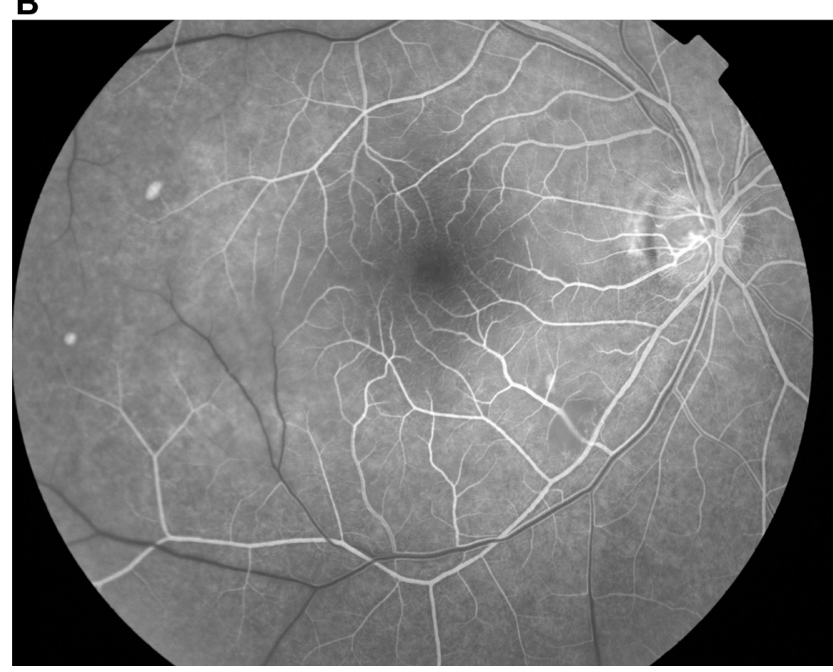

Figure 2 Fluorescein angiogram of the right eye showing late filling of the cilioretinal artery at over 30 seconds and choroidal perfusion defect due to block (A). Venous lamellar flow was observed at 43 seconds (B).

\section{Discussion}

Takanashi et $\mathrm{al}^{7}$ reviewed 17 cases of Churg-Strauss syndrome with ocular manifestations and classified them into two groups. One group $(n=8)$ was classified as the inflammatory pseudotumor type, the characteristics of which were a chronic onset of symptoms (7/8 patients), conjunctival involvement (8/8), orbital abnormalities on imaging studies (4/4), negative ANCA in examined cases $(0 / 3)$, no other cranial nerve involvement $(0 / 8)$, and good visual outcome in response to steroid therapy $(8 / 8)$. Another group $(n=9)$ was classified as the ischemic vasculitis type, the characteristics of which were sudden onset (7/9 patients), no lid or conjunctival involvement (0/9), no abnormalities on orbital imaging studies in examined cases $(0 / 2)$, positive ANCA in examined cases $(5 / 5)$, occasional involvement of the oculomotor and trochlear nerves (3/9), and occasional poor visual prognosis despite steroid therapy (5/9). Consequently, they concluded that the presence of ANCA is characteristic of the ischemic vasculitis type and that ANCA may be a risk factor for sudden visual loss. They further stated that prophylactic steroid therapy may be indicated to prevent potential visual loss. Subsequent to this report, similar cases of ANCA-positive patients with Churg-Strauss syndrome who developed severe bilateral CRAO were reported. ${ }^{3}$

On the other hand, there have been several published reports of CRVO in ANCA-negative Churg-Strauss syndrome. ${ }^{8-10}$ Our patient also had CRAO with ANCAnegative Churg-Strauss syndrome and was given high-dose corticosteroids regardless of ANCA status, and her macular edema soon improved. This treatment appeared to be beneficial, although it is difficult to rule out the possibility that her macular edema improved as part of the natural course of CRAO.

Although both proteinase-3-ANCA and MPO-ANCA were negative and C-reactive protein, white blood cell count, and blood coagulation were within normal limits, the likely cause of CRAO was thought to be the underlying vasculitis and secondary localized thrombosis. This case is novel, and the pathogenesis is still unclear. Further study in this area is needed.

In conclusion, patients with Churg-Strauss syndrome, whether or not positive for ANCA and even if no visual symptoms are present, should be carefully examined and treated with high-dose steroids to prevent potentially irreversible vision loss from ischemic-type ocular manifestations.

\section{Acknowledgment}

We thank Takeshi Tominaga and Kazuyoshi Magome for their technical support with this research.

\section{Disclosure}

The authors report no conflicts of interest in this work.

\section{References}

1. Masi AT, Hunder GG, Lie JT, et al. The American College of Rheumatology 1990 criteria for the classification of Churg-Strauss syndrome (allergic granulomatosis and angiitis). Arthritis Rheum. 1990; 33: 1094-1100.

2. Perez VL, Chavala SH, Ahmed M, et al. Ocular manifestations and concepts of systemic vasculitides. Surv Ophthalmol. 2004;49:399-418.

3. Udono T, Abe T, Sato H, Tamai M. Bilateral central retinal artery occlusion in Churg-Strauss syndrome. Am J Ophthalmol. 2003;136: $1181-1183$ 
4. Man BL, Fu YP, Shum KS, Mok CC. Bilateral central retinal artery occlusion in a patient with Churg-Strauss vasculitis. Clin Exp Rheumatol. 2011;29(1 Suppl 64):S137.

5. Guillevin L, Lhote F, Jarrousse B. Treatment of polyarteritis nodosa and Churg-Strauss syndrome. A meta-analysis of three prospective controlled trials including 182 patients over 12 years. Ann Med Interne (Paris). 1992;143:405-416.

6. Guillevin L, Visser H, Noel LH, et al. Antineutrophil cytoplasm antibodies in systemic polyarteritis nodosa with and without hepatitis B virus infection and Churg-Strauss syndrome - 62 patients. J Rheumatol. 1993; 20:1345-1349.

7. Takanashi T, Uchida S, Arita M, Okada M, Kashii S. Orbital inflammatory pseudotumor and ischemic vasculitis in Churg-Strauss syndrome (report of two cases and review of the literature). Ophthalmology. 2001;108:1129-1133.
8. Hoffman PM, Godfrey T, Stawell RJ. A case of Churg-Strauss syndrome with visual loss following central retinal artery occlusion. Lupus. 2005; $14: 174-175$.

9. Hamann S, Johansen S. Combined central retinal artery and vein occlusion in Churg-Strauss syndrome: case report. Acta Ophthalmol Scand. 2006;84:703-706.

10. Türkçüoğlu P, Isik A, Deniz N, Turgut B, Kan EK. Central retinal artery occlusion in an ANCA negative Churg-Strauss syndrome patient. Int Ophthalmol. 2007;27:369-371.
Clinical Ophthalmology

\section{Publish your work in this journal}

Clinical Ophthalmology is an international, peer-reviewed journal covering all subspecialties within ophthalmology. Key topics include: Optometry; Visual science; Pharmacology and drug therapy in eye diseases; Basic Sciences; Primary and Secondary eye care; Patient Safety and Quality of Care Improvements. This journal is indexed on

\section{Dovepress}

PubMed Central and CAS, and is the official journal of The Society of Clinical Ophthalmology (SCO). The manuscript management system is completely online and includes a very quick and fair peer-review system, which is all easy to use. Visit http://www.dovepress.com/ testimonials.php to read real quotes from published authors. 